\title{
A diez años del reconocimiento del derecho al matrimonio igualitario en México'
}

\section{Ten years after the recognition of the of the right to same-sex marriage in Mexico}

\section{Diego Alejandro Botero Urquijo (D)}

Unidades Tecnológicas de Santander, Colombia

diegoalebo24@gmail.com

\section{Unidades Tecnológicas de Santander, ColombiaResumen}

Este texto reconstruye la trayectoria que tuvo el reconocimiento de derechos de la población sexualmente diversa que llevó al reconocimiento del derecho matrimonio igualitario en el Distrito Federal, México, durante el año 2010. Después de ello, se analiza el tratamiento que dio la Suprema Corte de Justicia de la Nación al matrimonio igualitario a partir del litigio estratégico llevado a cabo por las minorías sexuales. A partir de allí, se analiza el impacto que ha tenido la regulación del matrimonio igualitario en la capital del país, en los demás Estados de la República y en el estatus actual de este derecho a nivel nacional.

Palabras clave: matrimonio igualitario, movilización social, movilización legal, aliados políticos.

\begin{abstract}
This text reconstructs the trajectory of the recognition of the rights of the sexually diverse population, this come to the regulation of same-sex marriage in the Federal District in 2010. It analyzes the impact that its recognition has had on others states of the Mexican Republic, in order to analyze the current status of this right.
\end{abstract}

Keywords: same-sex marriage, social mobilization, legal mobilization, political allies.

Articulo: Recibido el 20 de mayo de 2020 y aprobado el 27 de octubre de 2020

\section{Cómo citar este artículo:}

Botero, D. (2020). A diez años del reconocimiento del derecho al matrimonio igualitario en México. Reflexión política 22(46), pp. 73-86. doi: https://doi.org/10.29375/01240781.3910

\section{Introducción}

Este texto tiene dos objetivos principales: reconstruir el tránsito requerido para el reconocimiento del derecho al matrimonio igualitario llevado a cabo en el D.F. (Distrito Federal) de México en el año 2010 y analizar, de manera crítica, el desarrollo jurídico que tuvo el asunto sobre el matrimonio igualitario, a nivel nacional, a partir de la legislación del 2010 en el D.F.

En este sentido, se muestran las condiciones que se requirieron para que se llegara a la consecución de una ley que regulara el matrimonio igualitario y la adopción homoparental, y que fueron producto de las acciones colectivas y la movilización social que llevaron a cabo las minorías sexuales en el D.F. Esto con el objetivo de mostrar que los factores principales que explican el éxito de la regulación del

${ }^{1}$ Este texto surge de la investigación doctoral titulada Matrimonio igualitario en Argentina, México y Colombia 1993 - 2016, llevada a cabo en el Doctorado en Ciencias Políticas y Sociales de la Universidad Nacional Autónoma de México. 
matrimonio igualitario fueron: la movilización social en pro de los derechos de las minorías sexuales, las redes de acción política que se consiguieron con actores políticos y la movilización legal que impulsó las demandas requeridas. Estas desarrolladas en el marco de un contexto de expansión de la democracia a causa de las transformaciones políticas que se dieron en el D.F.

Después de ello se analiza el impacto que tuvo esta legislación a nivel nacional a partir del desarrollo que tuvo el asunto en la Suprema Corte de Justicia de la Nación (CSJN), donde se llevó a cabo un litigio estratégico por parte de las minorias sexuales con el objetivo de que se sentaran precedentes judiciales frente al reconocimiento del derecho al matrimonio igualitario.

En este sentido, se establece un análisis de los efectos que tuvo el proceso de reconocimiento del derecho al matrimonio igualitario en el D.F y del tratamiento realizado por la SCJN en el reconocimiento de este derecho en los Estados de la República.

\section{Movilización social por la diversidad sexual y de género}

La movilización social en pro de la diversidad sexual en México tiene sus primeras apariciones durante la década de los 70. En el marco de las movilizaciones que por la época agrupaban a diferentes grupos sociales, promovian la maximización de libertades políticas y sociales y demandaban transformaciones sociales por parte de los ciudadanos, aparecen las acciones colectivas en pro del reconocimiento de las minorías sexuales (Olvera, 1999). En 1971 se establece la primera organización homosexual en el país: EL Movimiento de Liberación Homosexual (Figari, 2010). Sus acciones se concentraban en compartir las experiencias de discriminación a las que eran sometidos los miembros de la población diversa y visibilizarlas en el marco de debates sobre las libertades y la sexualidad (Díez, 2011).

Sin embargo, el contexto político del país marcó un importante escenario que llevó al movimiento a operar desde la clandestinidad a partir del aumento de la represión estatal frente a las diferentes expresiones de protesta social. Dada la relación de miembros de la población diversa con diferentes grupos estudiantiles, obreros y de izquierda, las expresiones de diversidad sexual empezaron a verse como algo subversivo. El presidente del momento, Luis Echeverría, lo señaló en su cuarto informe presidencial, señalando la participación de miembros de las minorías sexuales en acciones terroristas (Lumsden, 1991).

A partir de estos acosos y con el impulso de personas socialmente relevantes, como Carlos Monsivais, José Joaquin Blanco y Luis Gonzales de Alba, durante la década de los 70 el movimiento comenzó la reivindicación del reconocimiento de la diversidad sexual. Desde un discurso liberacionista se exigió el cese del acoso policial a las minorías sexuales y se desarrolló una crítica a la concepción tradicional de familia (Díez, 2011). Ya para 1979 se habían organizado en el Distrito Federal el Frente Homosexual de Acción Revolucionaria, el Grupo Lambda de Liberación y Okiabeth, organizaciones sociales por la diversidad sexual. Además, ese año se organizó la primera manifestación en América Latina que resaltaba el orgullo gay, protestas sociales que se hacían en Estados Unidos y en otras partes del mundo en conmemoración a los sucesos de Stonewell (González, 2005).

Este periodo, que va desde la década del 70 hasta la década del 80 se conoce como "los años dorados" del movimiento por la diversidad sexual en México. Desde una fuerte crítica a la sexualidad hegemónica, hasta desarrollos teóricos en estudios sobre diversidad sexual le significaron al movimiento relaciones con sectores politicos y sociales que luchaban por los derechos de las mujeres y por transformaciones sociales en pro de una sociedad más democrática.

En la década del 80, a causa de disputas al interior del movimiento, se genera una fractura en el mismo que redunda en pérdida de visibilidad en la opinión pública. Además, las crisis económicas de la década tuvieron un efecto significativo, ya que representaron una reducción de los recursos requeridos para llevar a cabo las acciones colectivas y mostraron la incapacidad del movimiento social de enmarcar sus demandas en los discursos sobre las necesidades económicas del país. Claramente las crisis económicas 
superaron los discursos liberacionistas que se habían implementado durante las movilizaciones anteriores (Salinas, 2008).

Además de ello, la aparición del VIH/ SIDA, que afectó de manera contundente a la población sexualmente diversa, generó que esta se abanderara de la reivindicación de políticas públicas que atendieran los efectos de la enfermedad. Para esta época la trasmisión del VIH se convirtió en un problema de salud pública que afectaba principalmente a las minorias sexuales. El brote del VIH en México durante estos años tuvo un impacto muy alto en el movimiento por la diversidad, se puede decir que devastó su dirigencia y diezmó a sus miembros. Pero, además, transformó su actividad, ya que se estableció, como meta principal del movimiento, la supervivencia misma de sus miembros. Se dio un giro introspectivo pues abandonaron la búsqueda de los debates públicos sobre la sexualidad diversa, en gran medida por la fuerte reacción de la sociedad al brote del VIH, ya que las minorías sexuales eran culpadas por la enfermedad. Esto generó un discurso persecutorio y una serie de acciones violentas contra ellos, en las que el virus fue llamado la "plaga gay" o el "cáncer rosa” (Monsivais, 1998), lo que llevó a los activistas a concentrarse en procesos de autoayuda al interior del movimiento.

En 1987, la ONG Grupo Orgullo Homosexual de Liberación del Estado de Jalisco comenzó a realizar eventos respecto a la temática, en los que participaron funcionarios de Estado de Jalisco (Lázaro, 2014). Ese mismo año, el PRI (Partido Revolucionario Institucional) organizó páneles de discusión a los que se invitó a los activistas $\mathrm{y}$, a nivel federal, fueron invitados a participar en negociaciones para la reforma a la ley de la salud. En 1986 se había creado el Comité Para la Prevención del SIDA, y por decreto presidencial en el año 1988 se estableció el Consejo Nacional para la Prevención del SIDA (CONASIDA) (Gutiérrez et al., 2004). Este escenario le brindó al movimiento por la diversidad sexual una nueva plataforma en la que se organizó la acción colectiva, ya que se iniciaron contactos y trabajo en equipo con sectores de la sociedad que apoyaban las reivindicaciones en términos de salud, además con actores estatales en la promoción de condiciones para la atención del VIH/SIDA.

En un principio las relaciones entre los activistas por la diversidad sexual y el Estado estaban basadas en la confrontación, con el paso del tiempo éstas se transformaron en procesos de colaboración entre las partes. Para la década del 90 los activistas eran tenidos en cuenta en los procesos de formulación de políticas públicas que se desplegaban para la atención de la enfermedad. Toda la atención desplegada por el Estado, a partir de la Norma Oficial del presidente Zedillo del 17 de enero de 1995, en la que se asignaba a las instituciones gubernamentales la tarea de atender la enfermedad, solicitaba que se hiciera de manera conjunta con las minorías sexuales. Estas alianzas fueron muy significativas para el movimiento ya que le brindaron una plataforma de redes de acción política que sería crucial para la reivindicación de sus derechos (Salinas, 2008).

Hay que señalar que la atención del VIH/ SIDA en México, reivindicada por el movimiento social por la diversidad sexual en el país, permitió también enmarcar el discurso de la prevención y atención de la enfermedad en discursos sobre la sexualidad que se ubicaron en debates más generales sobre los derechos humanos. La idea de llevar el tema del VIH-SIDA al plano de los debates sobre la sexualidad, en el marco de los derechos, significó un enfoque discursivo que, apoyado en las redes de acción política, le permitió al movimiento social nuevas oportunidades políticas que se capitalizarían en la legislación del matrimonio igualitario, ya que las luchas por condiciones de justicia para estas comunidades requerian transformaciones legislativas (Díez, 2006).

En este contexto se genera una coyuntura muy importante para el país y por tanto también para el activismo social en pro de la diversidad sexual. Durante la segunda mitad de la década del noventa, el proceso de expansión del sistema político en México se aceleró de manera contundente. Los procesos de reformas politicas llevadas a cabo en esa época condujeron a que el partido hegemónico PRI (Partido Revolucionario Institucional) redujera su mayoría en la cámara de diputados y a que la jefatura de gobierno en el D.F. en el año de 1997 la obtuviera el partido de izquierda PRD (Partido de la Revolución Democrática), en tanto se estableció la elección del jefe de gobierno de la ciudad por voto popular (Marván, 2001). El ascenso del PRD a la jefatura de gobierno en la ciudad, en tanto partido de tendencia progresista en ese momento, le significó al movimiento social por la diversidad sexual una oportunidad para reivindicar sus demandas. 
Con este nuevo escenario en el sistema político mexicano, se consolidaron importantes relaciones con actores estatales y no estatales a partir de las luchas libradas contra la epidemia del VIH-SIDA. Estos avances llevaron a que desde la jefatura de gobierno del PRD, partido que era cercano al movimiento por la diversidad sexual, se llevara a cabo en 1998 el Primer Foro de Diversidad Sexual y Derechos Humanos, con el objetivo de discutir y definir las prioridades y exigencias del movimiento (Diez, 2006).

El encuentro sirvió para la organización del movimiento y como punto de partida en pro de las exigencias reivindicadas. Una vez profesionalizado, y con aliados importantes, el movimiento estructuró su discurso sobre la diversidad sexual en el marco de debates nacionales más grandes sobre los derechos humanos y la democracia (Monsivais, 2004). Esto generó un escenario en el que pasaron de la visibilización y el debate sobre la diversidad sexual, a la reivindicación específica de derechos para las minorías sexuales.

\section{Actores políticos y sociales en pro del reconocimiento de derechos}

Uno de los principales elementos que explica el apoyo político recibido para la legislación del matrimonio igualitario, tiene sus raíces en los gobiernos perredistas que tuvieron la jefatura de gobierno del D.F. desde 1997. El primer gobierno del PRD en 1997-1999, de Cuauhtémoc Cárdenas, se caracterizó principalmente por la reafirmación de derechos políticos en el proceso de transición a la democracia. Concentrado en temas de política social desde la construcción de un marco jurídico, este gobierno se concentró en el establecimiento de la institucionalidad requerida para ello, a pesar del corto tiempo de gobierno y de los limitados recursos con los que contó.

En el caso mexicano se observa una plataforma política (desde los gobiernos del PRD que estuvieron en la jefatura del D.F. desde $1997 \mathrm{al}$ 2012) que promovió una maximización de derechos. Esto da cuenta de que las oportunidades políticas que permitieron la legislación del matrimonio igualitario en el D.F. no se desprenden de una coyuntura política sino de una plataforma partidista en la que los gobiernos en el D.F. promovieron el reconocimiento de derechos.
Del Foro sobre Diversidad Sexual y Derechos Humanos realizado en 1998, y coordinado por el diputado David Sánchez Camacho, resultó el acuerdo por la importancia de luchas por la reivindicación de derechos civiles para las minorías sexuales, dando una nueva cara al movimiento social por la diversidad sexual. Como resultado del debate, se acordaron 3 puntos cruciales para la reivindicación de los derechos de las minorías sexuales: la protección legal de gays y lesbianas frente a la discriminación, la extensión de los beneficios de seguridad social para parejas del mismo sexo y la legalización del matrimonio igualitario. Si bien para muchos la iniciativa era prematura, se buscaba con este punto visibilizar la problemática para dar su discusión cuando se hubiera ganado terreno en los otros aspectos (Díez, 2015).

Como resultado del foro, también se observó lafirme convicción de conseguir las transformaciones sociales que reivindicaran los derechos de las minorías sexuales por el camino legislativo. Para ello, la conformación de grupos sociales con una base amplia fue un elemento fundamental de la estrategia. De manera simultánea, las minorías sexuales comenzaron a visibilizar los crímenes de odio contra miembros de la población sexualmente diversa, principalmente asociados a asesinatos por homofobia. En una comisión liderada por la ONG Letra $\mathrm{S}$, se conformó un comité contra la homofobia al que se integraron intelectuales y feministas como Carlos Monsiváis, Elena Poniatowska, y Marta Lamas. Éste se encargó de registrar estos crímenes y visibilizarlos en los medios de comunicación, con el objetivo de sensibilizar a la opinión pública. Vale la pena resaltar que los informes recolectados por este comité fueron un insumo muy importante para la transformación del código penal que se llevó a cabo en el D.F. en el año 1999, en el que se establecieron penas severas para crímenes de odio cometidos contra una variedad de grupos sociales discriminados históricamente, entre ellos, las minorías sexuales (Díez, 2015).

De igual manera, después del foro, las minorías sexuales comenzaron a presionar al gobierno del PRD en el D.F. para que se promoviera una legislación por la no-discriminación en relación con la diversidad sexual. A partir de la receptividad de la jefatura de gobierno, y con el apoyo de los diputados David Sánchez Camacho y María de 
los Ángeles Correo, se empezó a promover una regulación legislativa frente a esta temática.

Vicente Fox, elegido para el periodo presidencial 2000-2006, promovió una reforma constitucional que prohibía todas las formas de discriminación, la cual entró en vigor en el año 2001. Además, en su discurso incorporó la necesidad de proteger a las minorías sexuales de las diversas formas de discriminación a las que están expuestos. Una vez ejerció funciones como presidente, designó a Gilberto Rincón Gallardo como presidente de la comisión ciudadana encargada de estudiar las diferentes manifestaciones de discriminación, la cual se estableció en marzo del 2001. Esta comisión estaba compuesta por alrededor de 160 miembros, entre los que destacaban académicos, activistas, funcionarios gubernamentales de diversos partidos políticos y miembros sobresalientes de las minorías sexuales. Después de un arduo trabajo de campo, en el año 2002 la comisión presentó un informe y un proyecto de ley que pretendía una lucha contra la discriminación. Las labores de la comisión, después de construido el informe y el proyecto, se concentraron en promover campañas educativas para que se fomentara una cultura de tolerancia en el país. El proyecto fue enviado de manera muy rápida por el ejecutivo y en el año 2003 las dos cámaras del congreso lo aprobaron. Esta ley fue la primera que se promulgó en México para proteger a las minorías vulnerables y, como efecto de ella, se creó el Concejo Nacional para Prevenir la Discriminación (CONAPRED) (Díez, 2015).

La promulgación de esta ley abrió un escenario muy valioso para la lucha social de las minorías sexuales a nivel subnacional. En casi la mayoría de los Estados de la federación existían disposiciones legales que promovían "la moral y las buenas costumbres", los cuales eran utilizados para reprimir a las personas sexualmente diversas. Con la ley antidiscriminación los activistas consiguieron una plataforma para hacer visible que estas disposiciones legales eran inaplicables, encontraron un escenario para promover campañas en contra de la homofobia y para promover las demandas por las situaciones de discriminación generadas desde las disposiciones de los códigos civiles estatales (Díez, 2010).

Con la crisis del VIH en México durante las décadas del 80 y el 90, las minorías sexuales reconocieron la importancia de extender los derechos que se reservaban exclusivos para las parejas heterosexuales. En términos de seguridad social, los servicios, las pensiones y la propiedad común entre parejas eran exclusivas de parejas de diferente sexo, por lo que se abanderaron esos temas. Así que, a partir de las relaciones existentes con el PRD y la conformación de la ONG Diversa que había establecido alianzas con el PSD (Partido Socialdemócrata), se lanzó la campaña por la legislación de uniones civiles en el D.F. bajo la dirección de la diputada Enoé Uranga y su suplente y activista Arturo Díaz (Díez, 2015). La estrategia que también recogió a figuras importantes del activismo social como el director de Letra S Aejandro Brito y el abogado Rodolfo Millán. Además, la participación de grupos sociales y actores representativos del campo artístico y la opinión pública, promovió un debate público sobre las uniones civiles y su importancia en el marco de los derechos de los ciudadanos, con el objetivo de presionar por la legislación de uniones civiles. Como resultado de esta apuesta se estableció la Red Ciudadana de Apoyo a las sociedades de Convivencia como plataforma para presionar por la consecución de uniones civiles (Díez, 2010).

En 2003, la diputada Uranga presentó el proyecto, sin embargo, la red establecida para impulsarlo no logró conectarse con el entonces jefe de gobierno del D.F.: Andrés Manuel López Obrador, quien se opuso firmemente a la iniciativa y dio instrucciones a los diputados de su partido (PRD) para que se opusieran. A pesar de ser un partido de izquierda, López Obrador representaba un ala conservadora de la izquierda mexicana y había establecido en ese momento alianzas muy sólidas con la Iglesia católica, sectores que se oponían abiertamente a la regulación de uniones civiles. En tanto el PRD tenía mayoría en la asamblea legislativa y tras la oposición del ejecutivo en cabeza de López Obrador, el proyecto no logró su victoria en el escenario legislativo del D.F. A pesar de ello, en la opinión y los debates públicos, se había ganado mucho terreno estableciendo la necesidad de las uniones civiles como un tema crucial para los derechos y la democracia en el país.

En el 2006, con la llegada de Marcelo Ebrard a la jefatura de gobierno del D.F. por el PRD, se abre una ventana de oportunidad política para impulsar la ley de uniones civiles que no se consiguió en el mandato de López Obrador, dada la disposición de Ebrard a abanderar las reivindicaciones de 
las minorias sexuales. Con Ebrard, se permitió impulsar en el 2006 la ley de uniones civiles desde el ejecutivo. En un lapso de tiempo muy corto, la asamblea discutió la iniciativa y la aprobó para que fuera promulgada el mismo año (Díez, 2013).

\section{Agenda del matrimonio igualitario en el D.F.}

Las uniones civiles no fueron la única iniciativa que se impulsó en su periodo respecto a temas de derechos humanos. La visión de gobierno de Ebrard se enfocó en la promoción de los derechos sociales en México. En el D.F. se reconocieron derechos sociales con el fin de mejorar la calidad de vida y el bienestar de los ciudadanos. También, se manifestó la importancia de llevar estas reformas al nivel federal con el fin de construir una mejor democracia, desde la autonomía de la ciudad y su capacidad de impacto a nivel nacional. Durante su mandato, pocos meses después de que asumiera el poder, se reformó el código penal para permitir a las mujeres embarazadas el aborto fuera de los casos excepcionales de riesgo de vida de la madre, violación o malformación del feto. De igual manera, se legislaron reformas para acortar los procesos de divorcio, permitir la eutanasia pasiva y la legislación para penalizar crímenes de odio. Estas reformas, dan cuenta de una agenda progresista en la cual el matrimonio igualitario tuvo un espacio importante (Díez, 2015).

Con este panorama político, tras las reformas promovidas por Ebrard en el D.F., a nivel nacional se generó un debate en el que las fuerzas políticas conservadoras promovieron mecanismos para frenar la expansión de estas reformas en los demás Estados de la República. Con la llegada a la presidencia de Felipe Calderón, del PAN, en 2008 se promovió ante la Suprema Corte de Justicia de la Nación, en cabeza del entonces Fiscal General de la Nación, un intento por derogar la legislación que permitió la interrupción voluntaria del embarazo, argumentando que las regulaciones del servicio de salud son nacionales y que con esta práctica se viola el derecho a la vida. La corte falló en ese mismo año y dejó en firme la ley que permite tal interrupción en el D.F. Frente a ello, el PAN promovió en los Estados de la Federación reformas constitucionales con el objetivo de blindar su prohibición, logrando en 2012 que diez de los 32 Estados establecieran regulaciones que lo prohíben de manera explícita.
Respecto al matrimonio igualitario, el efecto en el ámbito subnacional fue similar, partidos como el PAN y facciones conservadoras del PRI se opusieron a que el debate se generara en otros Estados de la República.

En medio de un contexto tan ambivalente la diputada Uranga, elegida senadora en 2009, promovió una reforma constitucional que se concentraba en varios puntos: reformas a la seguridad social que expandieran los beneficios a las parejas del mismo sexo que habían establecido uniones civiles en el D.F. y en Coahuila (en ese momento era el único Estado que también había establecido uniones civiles), a la ley de identidad de género, a la ley nacional contra la discriminación estableciendo sanciones penales; con el objetivo de prohibir la discriminación por orientación sexual.

A pesar de que el proyecto legislativo no tuvo un resultado óptimo, el movimiento social por la diversidad sexual logró introducir en la agenda legislativa el proyecto para reconocer el derecho al matrimonio igualitario. El aliado fundamental para este proceso fue el PSD, que adoptó una plataforma política propuesta por los movimientos LGBTI y otros sectores sociales en la que pretendía la reivindicación de derechos como el matrimonio igualitario. En cabeza de David Razú, líder del partido, quien en las elecciones de 2009 tuvo que participar como candidato independiente ya que el PSD no alcanzó el umbral, se comenzaron a promover los puntos clave de la reforma. En alianza con el PRD, Razú incluyó el reconocimiento de este derecho como uno de los ejes principales de su plataforma política en la agenda legislativa de la asamblea del D.F. en el año 2010.

\section{Proceso legislativo del matrimonio igualitario en el D.F.}

A partir de la elección de Razú en la Asamblea legislativa del D.F., se estableció la agenda política del matrimonio igualitario. Dentro de su estrategia, se pretendía un proceso de ágil cabildeo que impulsara la votación en corto tiempo después de las elecciones de los legisladores. El segundo paso consistía en desplegar las redes de acción política que se habían conseguido con años de lucha social, y principalmente con los procesos legislativos de uniones civiles en el D.F. tres años antes. Por último, se construyó un discurso a favor de la 
propuesta del matrimonio igualitario alrededor de la igualdad, la no discriminación y la expansión de la ciudadanía democrática, lo que mostraba la apuesta por el matrimonio igualitario como un asunto de derechos necesario para la democracia mexicana (Chávez, 2017).

La relación con la jefatura de gobierno fue muy importante, ya que desde la presidencia de la Comisión de Derechos Humanos y en coordinación con la Oficina del Jefe de Gobierno, se desarrolló un proyecto de ley que reformó el artículo $146 \mathrm{del}$ código civil con el objetivo de reconocer el derecho al matrimonio igualitario. Además, el 27 de septiembre del 2009, se creó la Sociedad Unida por el Derecho al Matrimonio Entre Personas del Mismo Sexo, organización que recogió otros activistas como Jaime López Vela y que tenía, como principal objetivo, recoger las relaciones con actores estatales y no estatales que se habían cosechado con años de luchas sociales para impulsar una coalición que presionara por la aprobación de la iniciativa legislativa. Esta coalición reunió un amplio grupo de personas involucradas en las reivindicaciones de derechos sexuales y reproductivos conseguida durante la década del 90 en México y que contribuyeron a la despenalización del aborto y la legislación de las uniones civiles. Participaron organizaciones concentradas en la promoción de los derechos sexuales y reproductivos como la Red Nacional por la Democracia y la Sexualidad, la Asociación Mexicana Para la Salud Sexual (AMSSAC) y la Federación mexicana de Educación Sexual y Sexología (FEMESS). También se vincularon grupos de mujeres como GIRH, Mujeres Católicas por el Derecho a Decidir, y el Observatorio Nacional de Ciudadanos para los Derechos de la Mujer. Además, se sumaron académicos e instituciones de investigación y educativas, y activistas de los movimientos LGBTI. El comité que comenzó con poco más de 30 personas, para final del año 2009 contaba con más de 300 .

El uso de los medios de comunicación web fue otro mecanismo para la promoción del matrimonio igualitario en la opinión pública, el 31 de octubre se lanzó una campaña por redes sociales y por youtube en el que se emitían contenidos que promovian la importancia del reconocimiento de este derecho. Desde esta plataforma mediática, el 10 de noviembre los promotores de la propuesta en la asamblea legislativa dieron una rueda de prensa en la que se hacía pública la intención de transformar el código civil del D.F. en coordinación con la oficina del jefe de gobierno. El 21 de noviembre se organizó en la asamblea un foro en pro del matrimonio entre personas del mismo sexo, en el que se debatió la importancia del matrimonio igualitario como un asunto de interés para la democracia mexicana (Díez, 2015).

El tema de la adopción fue también un elemento controversial, sin embargo tras discusiones y negociaciones, entre promotores y aliados, y con el argumento que sería excluyente permitir el matrimonio y no la adopción para parejas del mismo sexo, se incluyó en la iniciativa (Saucedo, 2012). Las reacciones no se hicieron esperar y se generaron diferentes opositores a la iniciativa. Por su parte, el PRD se dividió en un ala progresista que apoyaba el proyecto en consonancia con las posiciones del jefe de gobierno y en un ala cercana al ex jefe de gobierno López Obrador que no estaba de acuerdo. Sin embargo, con mayoría PRD a favor, y con el apoyo del ejecutivo se puso a andar la iniciativa. Alrededor de 40 diputados la apoyaron, soportada por firmas de más de 300 personas y organizaciones, se envió a la asamblea el proyecto el 23 de noviembre del año 2009.

La oposición a la iniciativa vino principalmente desde el PAN, sin embargo, no se pudo ver un hilo argumentativo sólido como el que construyeron los promotores del matrimonio igualitario. En medio del debate, la Iglesia católica mostró también una férrea oposición al proyecto, el Vicario Episcopal Jonás Guerrero Carmona manifestó públicamente que lamentaba el apoyo dado por la comisión de derechos humanos de la asamblea al proyecto, y que la Iglesia católica se opondría al mismo a partir de los principios de la ley natural. En un sentido muy similar, el Cardenal Javier Lozano Barragán, ministro de salud del vaticano, a propósito del debate en México, señaló que la homosexualidad es un pecado en contra de las leyes naturales y divinas (Díez, 2015).

La primera votación se realizó en comisión el 11 de diciembre del 2009, obteniendo un resultado de diez votos a favor y cuatro en contra. Tras esta primera victoria, a pesar de las maniobras del PAN para detener el curso del proyecto, se incrementó el debate público sobre su conveniencia. El PAN, que hasta el momento no se esperaba que la iniciativa llegara tan lejos, comenzó a presionar con 
el argumento que ese proyecto afectaría el sistema de seguridad social que es de ámbito federal. De la misma manera, la Iglesia católica se opuso defendiendo la tradición del matrimonio como una institución natural que tiene como finalidad única la procreación. A partir de ese discurso y tras ver que la iniciativa ganaba terreno, estos sectores comenzaron a promover que el asunto debía ser consultado mediante un referéndum. Sin embargo, esta moción fue rechazada en la asamblea el 16 de diciembre de 2009 (Saucedo, 2012).

Tras el primer triunfo en la asamblea legislativa, el debate público se hizo todavía más álgido, los activistas y promotores, coordinados por Razú y Castañeda, promovieron el apoyo en los medios de importantes personalidades de la opinión pública como el periodista Sergio Sarmiento y el académico y activista por los derechos humanos Sergio Aguayo, así como del presidente del Consejo Nacional Contra la Discriminación Ricardo Bucio. En el contexto mediático el discurso se concentraba en mostrar que ni el reconocimiento del derecho al matrimonio igualitario ni la posibilidad de adopción para parejas del mismo sexo tiene efectos nocivos en los niños y que promoverlo es positivo para la democracia en tanto es un tema de derechos.

El día de la votación, tras varios intentos fallidos del PAN por aplazar la votación y dada la velocidad con la que se tramitó el proyecto sin una oposición que tuviera una sólida argumentación, fue votado el 21 de diciembre del 2009. Se aprobó con treinta y nueve votos a favor, veinte en contra y cinco abstenciones. Acto seguido, la diputada Contreras solicitó una enmienda para que se permitiera la adopción homoparental, la cual fue votada con 31 votos a favor, veinticuatro en contra y nueve abstenciones. Cabe resaltar que en ambas votaciones, todos los miembros del Partido Verde y del PAN votaron en contra de la propuesta (Saucedo, 2012).

En los días siguientes a la votación, sectores del catolicismo se pronunciaron públicamente señalando la legislación como un atentado contra la Iglesia y la familia y una falta a las leyes naturales que para ellos organizan la vida en comunidad, tal como lo expresó el cardenal Norberto Rivera. También se unieron a los pronunciamientos sectores protestantes, que con la Iglesia católica solicitaron al jefe de gobierno Marcelo Ebrard vetar la legislación. En el mismo sentido, el PAN y el Partido Verde solicitaron el veto por parte de la jefatura de gobierno y comenzaron un proceso de litigio para impugnar la legislación en la Suprema Corte de Justicia de la Nación. En este contexto se generaron serias disputas entre la iglesia católica y el PRD en las cuales la iglesia rompió diálogos con el partido (Díez, 2015). Es importante señalar que después de la votación en la asamblea los argumentos se concentraron en la presunción del derecho de los niños a tener una familia tradicional y en los peligros que para ellos podría conllevar el matrimonio homoparental. Numerosas intervenciones en la opinión pública dan cuenta de las confrontaciones de ambas partes en las que se evidencia un acalorado debate en una población polarizada frente a estos temas. Así, la promulgación de la ley se aplazó para el año siguiente y fue promulgada el 4 de Marzo del 2010, haciendo de México el segundo país de América Latina en donde se legisló el reconocimiento del derecho al matrimonio igualitario.

Es importante señalar que, dado el sistema político federal mexicano, la regulación de asuntos como el matrimonio y la adopción es de orden subnacional, lo que quiere decir que cada Estado tiene autonomía para regular el asunto de manera independiente. Sin embargo, su reconocimiento en el D.F. significó un logro de alto impacto para la lucha por expandir este reconocimiento a los demás Estados, la cual comenzaría a partir del 2010.

\section{Jurisprudencia de la Suprema Corte de Justicia de la Nación}

A partir de la legislación del matrimonio en el D.F. el PAN intentó infructuosamente impugnar la constitucionalidad de la ley ya que, según la reglamentación, se debe tener el 33\% de los votos de la asamblea para ello. Sin embargo, desde el Gobierno Nacional en una confrontación política de muy alto calibre, el presidente Calderón impugnó la constitucionalidad de la ley con la intención de interferir en la autonomía del D.F. para legislar el derecho al matrimonio igualitario. El procurador general de la República, mediante un escrito presentado el 27 de enero del 2010 ante la Suprema Corte de Justicia de la Nación, solicitó una acción de inconstitucionalidad de la validez del artículo 146 del código civil del D.F. que había sido 
modificado para reconocer el derecho al matrimonio igualitario y del artículo 391 que, tras la legislación, permitió la adopción para las parejas del mismo sexo (García, 2017).

La solicitud de inconstitucionalidad pretendía demostrar que el matrimonio igualitario iba en contra del orden constitucional desde estos elementos:

1. La legislación del derecho al matrimonio igualitario en el D.F. se opone a la noción constitucional de matrimonio y de familia, sin que fuera constitucional la ampliación del matrimonio a parejas del mismo sexo, principalmente por no tener la posibilidad de procrear.

2. La norma del D.F. va en contravía de la legislación de los estados de la República que no reconocen el matrimonio igualitario, lo que genera conflictos normativos y jurídicos entre los Estados, además de generar una ruptura en el federalismo.

3. La adopción por parte de parejas del mismo sexo afecta el interés superior de los niños, que es protegido constitucionalmente (Quintana, 2018).

Durante gran parte del año 2010, la SCJN escuchó los argumentos de promotores y detractores de la reforma, lo que fue un hecho interesante en tanto abrió sus puertas a los principales actores sociales que hacian parte del debate. Posteriormente la sentencia fue emitida en el fallo de la Suprema Corte de Justicia de la Nación, en la acción de inconstitucionalidad 2/2010 el 16 de agosto del año 2010, por mayoría de nueve votos de sus integrantes a favor y dos en contra. Con tal fallo la Corte dejó en firme la legislación llevada a cabo en el D.F. a partir de los siguientes argumentos:

- Este caso refiere a un acto normativo que amplía un derecho civil con el objetivo de equiparar la protección jurídica tanto a parejas homosexuales como a parejas heterosexuales, desde la motivación del legislador del respeto al principio de igualdad y a la prohibición de no discriminación, específicamente a partir de la orientación sexual de los ciudadanos.

- Estableció que es competencia del legislador ordinario la regulación de los asuntos civiles según la regulación constitucional de la
República. Por tanto, la regulación de la institución del matrimonio, por parte del legislador del D.F., se encuentra cobijada desde el orden constitucional.

- Respecto a la familia, el artículo 4to. constitucional no alude a la institución del matrimonio ni lo define, sino que garantiza la protección de la familia como tal, cediendo al legislador la responsabilidad de regular todo aquello relativo a su organización. En este sentido, se rechaza el ideal de familia, entendida por el accionante (el Procurador General) como aquella comprendida por hombre mujer e hijos que nacen del matrimonio, por no ser el único tipo de familia que existe $y$, en esa medida, el único modelo que se debe proteger.

- Se reconoció que la familia antes que ser un concepto jurídico es un concepto sociológico que depende de las dinámicas socioculturales de cada época. En tanto su configuración actual es diversa, el legislador debe atender a la realidad social actual y proveer protección a todo tipo de familia.

- Se estableció que la constitución no define al matrimonio ni este es un concepto inmutable. Muestra de ello son las transformaciones sociales y los cambios que ha sufrido la regulación civil del matrimonio. Estos cambios han llevado a que se separe el matrimonio de una única función reproductiva, ya que, si bien es un elemento importante, en la actualidad los lazos afectivos, sexuales, de solidaridad y compromiso mutuo le dan sentido al matrimonio. Estos aspectos no son exclusivos de parejas heterosexuales, son compartidos también por parejas del mismo sexo.

- No vulnera la Constitución Federal que el legislador ordinario haya ampliado la figura del matrimonio a las parejas del mismo sexo, ya que lo hizo en pro de respetar el principio de igualdad y no discriminación, y en atención a la realidad social imperante.

Respecto a la adopción por parte de parejas del mismo sexo la corte determinó que no era inconstitucional a la luz de los principios de igualdad y no discriminación por razón de preferencia sexual, y del principio de interés superior del niño que 
consagran los artículos $1^{\circ}$ Y $4^{\circ}$ de la Constitución Mexicana. La Corte argumentó que, en tanto ya se había establecido que el matrimonio entre personas del mismo sexo es constitucional y que la familia es de naturaleza diversa, no podría sostenerse que las parejas del mismo sexo contrajeran matrimonio, pero no construyeran familia mediante la adopción.

De igual manera advirtió que la orientación sexual de una persona no puede, bajo ninguna circunstancia, tomarse como un motivo para determinar que esta persona pueda o no estar en condiciones de adoptar, eso sería discriminatorio. Estableció que el Estado debe asegurar, en pro del interés superior del niño, que los procesos de adopción signifiquen la posibilidad de una mejor vida para el menor. Además, señaló que el argumento esgrimido por el Procurador General de la Nación, en el que sostenía que los niños criados en familias homoparentales serían objeto de discriminación por no formar parte de una familia ideal, no puede ser aceptado pues refiere a una concepción tradicional de familia que no concuerda con la realidad actual, en la que las familias diversas existen con independencia de si pueden adoptar o no. También señaló que una conducta discriminatoria en una sociedad democrática sea cualquiera su origen, no puede persistir ni ser convalidada por el tribunal constitucional, mucho menos evitando que se configuren familias homoparentales o fingiendo que no existen

El fallo de la Suprema Corte de Justicia de la Nación respecto a la acción de inconstitucionalidad sobre la legislación del matrimonio igualitario en el D.F. tiene un antecedente en la sentencia de ese mismo tribunal, en el amparo directo civil 6/2008, en el que se atendió la problemática de personas transexuales en relación con su identidad de género. $\mathrm{El}$ amparo fue interpuesto por una persona de sexo masculino, que se sometió a una serie de tratamientos psicológicos y médicos, además de una cirugía de reasignación de sexo, con el objetivo de readecuar su sexo y su identidad de hombre a mujer. En ese sentido había solicitado, por medio de un juicio de rectificación de acta de nacimiento ante la autoridad judicial de lo familiar en el D.F., que le fuera expedida una nueva acta con el nombre de mujer con el que llevaba su vida cotidiana. El juez de lo familiar le dio la razón al demandante y le otorgó una rectificación de su acta de nacimiento en una nota marginal, tal como lo establecía la ley en ese momento, negándose a la expedición de una nueva acta de nacimiento. Frente a esta situación el sujeto interpuso un amparo directo reclamando que la legislación civil vulneraba sus derechos de igualdad, no discriminación, privacidad, salud y dignidad humana.

Frente a este amparo, la Corte determinó que la problemática de fondo se concentraba en el reconocimiento jurídico de una persona transexual y de sus derechos. A partir de allí, estableció que si bien derechos como el libre desarrollo de la personalidad, sexual y de género, no se encuentran reconocidos explícitamente en la Constitución, están implícitos en el ordenamiento jurídico del país y en los tratados internacionales que hacen parte del bloque de constitucionalidad, y en última instancia derivan del derecho a la dignidad humana reconocido en el artículo $1^{\circ}$ de la Constitución (García, 2017).

Con la sentencia emitida en el año 2010, el proceso en el Distrito Federal quedó saldado. Sin embargo, en el contexto jurídico nacional comenzó una fuerte movilización legal con el objetivo de extender el reconocimiento de este derecho a otros Estados de la República a partir de los fallos de la Suprema Corte de Justicia de la Nación. En el 2012, en el Estado de Oaxaca, tres parejas del mismo sexo solicitaron ante diferentes registros civiles se les uniera en matrimonio, lo que fue rechazado con base en el artículo 143 del código civil de Estado que establece el matrimonio como una unión exclusiva entre un hombre y una mujer. Estas parejas interpusieron amparos argumentando que se cometía una omisión legislativa al no incluir en la concepción del matrimonio a las parejas del mismo sexo y que se les discriminaba a partir de su preferencia sexual. En uno de los casos se concedió el amparo a las demandantes y en los otros dos no, afirmando que en el caso de una omisión legislativa la concesión del amparo podría violar los principios del juicio de amparo.

Las tres parejas solicitaron ante la primera sala encargada de asuntos civiles de la Suprema Corte de Justicia de la Nación que ejerciera su facultad de atracción a partir de la importancia del tema que se estaba tratando. En México, la Suprema Corte de Justicia de la Nación tiene la facultad de atraer asuntos que no se encuentran en un momento procesal idóneo para ser fallado por los tribunales y tratar temas relevantes para que sean resueltos por esta (Suárez, 2017). Frente a ello, la primera sala decidió atraer los casos y fallar de fondo, 
emitiendo las tres sentencias el 5 de diciembre de 2013. En ellas se determinó por unanimidad que a los demandantes se les había vulnerado el principio de igualdad y no discriminación, por lo que se les concedió el amparo.

Estos tres casos son muy importantes por sentar los precedentes en los cuales la Suprema Corte de Justicia de la Nación establece con base en una categoría sospechosa: que el matrimonio es una institución que busca formar una vida en pareja con lazos afectivos y sexuales, por lo que no hay argumento alguno para no reconocer tal derecho a parejas del mismo sexo. Hacerlo quiere decir que se tienen en cuenta prejuicios históricos sin sustento científico, jurídico, político y social, lo que conlleva un trato discriminatorio a partir de preferencias sexuales (Quintana, 2018).

En ese año, después de los fallos emitidos por la corte en esos tres casos, 39 personas presentaron amparos ante un juez de distrito aduciendo que el artículo del código civil de Oaxaca los discriminaba en función de su preferencia sexual en relación con su concepción de matrimonio tradicional. En este caso, los demandantes no solicitaban la posibilidad de casarse, ni se les había negado el matrimonio, argumentaban que, en función de una categoría sospechosa como la orientación sexual, la legislación del Estado los discriminaba. El juez de distrito sobreseyó el amparo al considerar que no se había probado su interés jurídico por parte de los demandantes y que se requería un acto de aplicación u omisión por parte de las autoridades para que se pudiera impugnar. Ante tal respuesta los demandantes solicitaron revisión del tribunal colegiado y este lo remitió a la primera sala de la Suprema Corte de Justicia de la Nación, quien, desde su facultad de atracción, y en tanto ya había fallado en los tres casos anteriores, decidió revisarlo y fallar al respecto.

En el fallo del Amparo en revisión 152/2013 la Corte determinó que era inconstitucional tanto la porción normativa del artículo 143 del código civil de Oaxaca que dice "perpetuar la especie", como la que establece "entre un solo hombre y una sola mujer". Señaló que esto no generaría vacío legal alguno pues la legislación civil estatal prevé los derechos y obligaciones de los cónyuges. Además, es muy importante resaltar que vinculó los efectos de la sentencia a todas las autoridades del Estado de Oaxaca, las cuales no podrán negar a los 39 demandantes beneficios ni podrán establecer cargas en lo relacionado con el matrimonio, por lo que las personas homosexuales no pueden ser expuestas al mensaje discriminador que tenía el código civil.

El Estado de Colima en el año 2013 incluyó en su código civil la figura del enlace conyugal, el cual era diferente al matrimonio que seguía concibiéndose como la unión entre hombre y mujer. Este enlace conyugal se estableció como la unión entre dos personas del mismo sexo con el objetivo de compartir una vida en común, por lo que se tuvieron que reformar varios artículos del código civil para conseguir tal distinción. En relación con el matrimonio, los contrayentes del enlace conyugal tenían los mismos derechos y obligaciones que los del matrimonio, a excepción de la adopción.

Frente a ello se instauraron diversas acciones legales, en los amparos 704/2014 y $735 / 2014$, la primera sala de la Suprema Corte de Justicia de la Nación determinó que la figura del enlace conyugal reproducía la idea de "separados pero iguales" ya que la distinción establecida entre ella y el matrimonio se basaba en la orientación sexual, la cual es categoría sospechosa. En la revisión de la figura del matrimonio se declaró inconstitucional su definición, además, se dio un pronunciamiento sobre los roles que establecía el código civil de Colima en lo que respecta al matrimonio, señalando que la asignación de roles específicos al interior del matrimonio o la familia, en función del sexo o el género, responden a una visión estereotípica basada en características sociales o culturales que son discriminatorias. También se determinó, en relación con el alegato a la adopción, que al declararse inconstitucional la creación de una figura paralela a la adopción, de igual forma a como sucedió con la definición de matrimonio entendido exclusivamente entre hombre y mujer, era evidente que las parejas del mismo sexo podían acceder a la figura del matrimonio $\mathrm{y}$, por tanto, adoptar.

A partir de los algunos de los precedentes descritos hasta ahora, la Suprema Corte de Justicia de la Nación emitió jurisprudencia genérica el 19 de junio del 2015 respecto a la inconstitucionalidad de la figura del matrimonio tradicional en la sentencia J. 45/2015. En tanto se determinó que la finalidad del matrimonio no es la procreación, no hay necesidad que este se configure exclusivamente entre hombre y mujer. También señaló que su sola enunciación es discriminatoria y estableció que ninguna norma, decisión o práctica de derecho interno, tanto de las autoridades o de particulares, 
puede afectar los derechos de cualquier persona en razón de su orientación sexual. Esta sentencia implica que la Corte establece un criterio obligatorio para todas las autoridades judiciales de la República en caso de analizar una norma con características similares. Además, envía un mensaje contundente a los cuerpos legislativos estatales respecto a las limitaciones que tiene para la legislación de la figura del matrimonio (Quintana, 2018).

En el año 2016, el Tribunal en Pleno de la Suprema Corte de Justicia de la Nación emitió sentencia frente a la acción de inconstitucionalidad $28 / 2015$, que cuestionaba la inconstitucionalidad del matrimonio tal como se concebía en el artículo 260 del código civil de Jalisco. Allí, la Corte determinó que era inconstitucional con base en la protección a las diferentes formas de familia establecida en el artículo 4to. constitucional a partir de las consideraciones establecidas en la acción de inconstitucionalidad 2/2010 sobre el matrimonio igualitario legislado en el D.F (Quintana, 2018).

En México se ha intentado replicar la experiencia del D.F. en los demás Estados de la República. Sin embargo, dadas las condiciones sociopolíticas de cada uno de ellos, ha sido difícil conseguir que se regule el matrimonio igualitario. A partir de las condiciones políticas propias de cada Estado, hasta el día de hoy se ha legislado el matrimonio igualitario en Coahuila, Baja California Sur, Campeche, Colima, Hidalgo, Michoacán, Morelos, Nayarit, Oaxaca, San Luis Potosí y La Ciudad de México. En el Estado de Quintana Roo se presenta una situación particular, ya que su concepción de matrimonio no ha especificado una determinación tradicional ni diversa, por lo que nunca se ha necesitado la transformación del código civil. En otros Estados es posible de facto el matrimonio igualitario, ya sea por mecanismos impulsados por el ejecutivo en atención a la jurisprudencia de la Suprema Corte de Justicia de la Nación, ya sea por mecanismos judiciales que permiten que el matrimonio entre parejas del mismo sexo se oficialice, o por otros mecanismos que responden a situaciones particulares de la realidad de cada Estado. En ese sentido, estos casos responden a la atención que, a nivel subnacional, se le presta a la jurisprudencia de la Corte respecto del matrimonio igualitario. Los Estados en los que a pesar de que no esté regulado se pueden casar las parejas del mismo sexo son: Aguascalientes, Baja California, Chiapas, Chihuahua, Jalisco, Nuevo
Leon, Puebla, Querétaro y Zacatecas. Por otro lado, los Estados en los que no es posible ni formalmente, ni de facto el matrimonio igualitario son: Durango, Estado de México, Guanajuato, Guerrero, Sinaloa, Sonora, Tabasco, Tamaulipas, Tlaxcala, Veracruz, Yucatán.

Es importante resaltar que, a partir de la jurisprudencia de la Suprema Corte de Justicia de la Nación, por vías judiciales es posible que se reconozcan en todo el territorio mexicano los matrimonios igualitarios que se oficialicen en Estados donde es posible contraerlo. Además, es posible llevar a cabo litigios estratégicos que impulsen la celebración de matrimonio entre personas del mismo sexo en Estados donde no está regulado.

En este contexto, es posible ver que en México existe un reconocimiento fragmentado. Si bien hay contundentes avances, las dinámicas políticas y jurídicas del país, las particularidades de su sistema político, los niveles de autonomía de los Estados y las condiciones sociales y culturales propias del país han llevado a que no se logre la regulación del matrimonio igualitario en todo el territorio (Salinas, 2017).

En el año 2016, el presidente Enrique Peña Nieto promovió una reforma constitucional para la regulación del matrimonio entre personas del mismo sexo. Este fue un proceso muy polémico, impulsado en un contexto en que la popularidad del presidente se encontraba en un bajo nivel. La iniciativa generó respuestas de grupos sociales y políticos conservadores aludiendo a la defensa de las leyes naturales y la protección de la familia tradicional. Se promovieron manifestaciones públicas en oposición a la reforma.

Desde el movimiento social por la diversidad sexual se intentó realizar lobby para conseguir que se regulara constitucionalmente este derecho. Sin embargo, su poca presencia fuera del D.F. hizo difícil conseguir el impacto requerido para impulsar la propuesta. Además, el el ejecutivo logró un impacto muy limitado ya que no contó con el apoyo de su partido para impulsar la propuesta, esta no pasó de la comisión constitucional del congreso. El 9 de noviembre de 2016, se realizó la votación con 19 votos en contra, ocho a favor y una abstención. Diputados del PRD y Morena apoyaron la iniciativa, mientras que diputados del PRI, PAN, y Partido Verde de México se opusieron. 
En su mayoría, los procesos jurídicos relacionados con el matrimonio igualitario han sido impulsados por la asociación México Igualitario, en alianzas con grupos y organizaciones locales y con base principalmente en las tesis de la Suprema Corte de Justicia de la Nación para el caso del D.F. (López, 2017). Este contexto da cuenta del reconocimiento desigual de derechos de la población sexualmente diversa. El que, a nivel subnacional, no se reconozcan estos derechos de manera homogénea da cuenta de que en el país hay lugares donde las personas pueden conformar familia, sin importar su sexualidad, y otros en los que no es posible. Se puede ver como algunos se ven obligados a ejercer sus derechos a partir de procesos judiciales, lo que a su vez se convierte en una situación tortuosa ya que la revisión de estas demandas es lenta y en muchos casos se presentan resistencias por parte de las autoridades. Además, ya que los amparos sólo tienen efecto para los involucrados, las cortes sólo invitan a los legisladores subnacionales a regular el matrimonio igualitario, pero en la actualidad sólo existen legislaciones en el 34\% del territorio.

\section{Observaciones finales}

La experiencia del reconocimiento del derecho al matrimonio igualitario en México muestra que, a pesar de las resistencias a la movilización social por la diversidad sexual en el país, el movimiento social se ha organizado y manifestado de manera eficiente en pro de conseguir sus demandas. Si bien los mayores impactos se han conseguido en el D.F., ahora Ciudad de México, también han existido logros a nivel nacional, los cuales contribuyen a que las minorías sexuales encuentren mejores condiciones de vida. Desde la lucha por el reconocimiento de la diversidad sexual, la contención del VIH/SIDA, el reconocimiento de derechos patrimoniales, el reconocimiento del matrimonio igualitario y la adopción, hasta el combate contra las diferentes formas de discriminación, exclusión y violencia por preferencias sexuales, es claro que el movimiento social por la diversidad sexual en el país es el protagonista central de las transformaciones obtenidas.

Esta experiencia además muestra que el reconocimiento de tal derecho requirió: condiciones políticas y jurídicas que permitieron el debate público sobre el tema, movilización legal que impulsó desde lo jurídico el reconocimiento de derechos de las minorías sexuales y aliados políticos que impulsaron las propuestas de regulación formal del matrimonio igualitario. Para el caso mexicano, el aliado político determinante fue el gobierno local de la época en el D.F., ya que, desde el ejecutivo, se consiguió el apoyo requerido para lograr el reconocimiento legislativo del derecho al matrimonio igualitario.

$\mathrm{Si}$ bien los logros son contundentes, al analizar el contexto nacional es posible hablar de un reconocimiento de este derecho de manera fragmentada, en tanto en algunos Estados se ha regulado, en otros de facto es posible para las parejas del mismo sexo contraer matrimonio y en otros tantos no hay ni regulaciones legislativas ni mecanismos que permitan los matrimonios homoparentales, por lo que su consecución sólo se logra a partir de arduos procesos jurídicos.

Con todo esto, el reconocimiento a la importancia del proceso llevado a cabo en México es un referente fundamental para la región, en tanto de sus características se puede y debe aprender muchos si se pretende conseguir transformaciones como esta en otros lugares. El movimiento social mexicano por la diversidad sexual, durante este arduo recorrido para conseguir el reconocimiento del derecho al matrimonio igualitario, ha demostrado que este debate es un tema indispensable para la democracia y para la construcción de sociedades igualitarias, por tanto, su experiencia es muy valiosa.

\section{Bibliografia}

Chávez, J. (2017). El matrimonio igualitario en México: Una aproximación contextual desde las prácticas sociopolíticas hacia las iniciativas de ley. Revista Ciudades, Estos y Política, 4(3), 87-101.

Díez, J. (2006). Political Change and Environmental Policymaking in Mexico. Nueva York, Estados Unidos: Routledge.

Díez, J. (2010). The Importance of Policy Frames in Contentious Politics: Mexico's 2005 AntiHomophobia Campaign. Latin American Research Review, 41(1), 33-54. https://doi. org/10.1353/lar.0.0091

Díez, J. (2011). A Queer Tango between the LG Movement and the State. En C. Jhonson, D. Paternotte \& M. Tremblay (Eds.), The lesbian and gay Movement and the State: Comparative Insigths into a Transformed Relasionship (pp.1325). Ashgate, London: Routledge. https://doi. org/10.4324/9781315556178-2

Díez, J. (2013). Explaining Policy Outcomes: The Adoption of Same-Sex Unions in Buenos Aires and 
Mexico City. Comparative Political Studies, 46(2), 212-235. https://doi.org/10.1177/0010414012453035

Díez, J. (2015). The Politic of Same-Sex Marriege in Latin América. Argentina, Chile And México. Cambridge, Estados Unidos: Cambridge University Press. https://doi.org/10.1017/CBO9781316162804

Figari, C. (2010). El movimiento LGBT en América Latina: Institucionalizaciones oblicuas. En A. Massetti, E. Villanueva y M. Gómez (Eds.), Movilizaciones, protestas e identidades políticas en la Argentina del bicentenario (pp.225-240). Buenos Aires, Argentina: Nueva Trilce.

García, L. (2017). La primera legislación sobre matrimonio igualitario y la suprema corte de justicia de la nación (acción de inconstitucionalidad 2/2010). En A. M. Alteiro y R. Niembro (Eds.), La suprema corte y el matrimonio igualitario en México (pp. 1-19). Ciudad de México, México: UNAM.

González, M. (2005). Marcha del orgullo por la diversidad sexual. Manifestación colectiva que desafía las políticas del cuerpo. El Cotidiano, 131, 90 - 97.

Gutiérrez, J., López, J., Valencia, A., Pesqueira, E., Ponce de León, S., y Bertozzi, S. (2004). Haciendo frente a la epidemia de VIH/SIDA en México: ¿Una respuesta organizada?. Revista de investigación clínica, 56(2), 242-252.

Lázaro, C. (2014). La conformación del movimiento LGBT en Guadalajara, Jalisco. Argumentos, 27(76), 241-273.

López, J. (2017). Los derechos LGBT en México. European Review of Latin American and Caribbean Studies, 104, 69-88. https://doi.org/10.18352/erlacs.10234

Lumsden, I. (1991). Homosexualidad, sociedad y Estado en México. Ciudad de México, México: Solediciones.

Marván, I. (2001). La cuestión del gobierno representativo en el Distrito Federal mexicano. Cuestiones Constitucionales, 4, 49-83.

Monsivais, C. (1998). Las plagas y el amarillismo. Notas sobre el sida en México. En F. Gañván (Ed.), El sida en México. Los efectos sociales (pp.117129). Ciudad de México, México: Ediciones de Cultura Popular.

Monsivais, C. (2004). La emergencia de la Diversidad: Las comunidades marginales y sus batallas por la visibilidad. Debate Feminista, 15(87), 187-205. https://doi.org/10.22201/cieg.2594066xe.2004.29.1019

Olvera, A. (1999). El concepto de movimientos sociales: Un balance inicial sobre su empleo en México (1970-1996). En J. Durand (ed.), Movimientos Sociales. Desafios Teóricos y Metodológicos (pp. 109-135). Guadalajara, México: Ediciones de la Universidad de Guadalajara.

Quintana, K. (2018). "La evolución judicial del matrimonio igualitario en México y su impacto en el reconocimiento de derechos". En A. Alterio y R. Niembro (Eds.), La Suprema Corte y el matrimonio igualitario en México (pp.21-54). Ciudad de México, México: UNAM.

Salinas, H. (2008). Politicas de disidencia sexual en México. Ciudad de México, México: CONAPRED.

Salinas, H. (2017). Matrimonio igualitario en México: La pugna del Estado laico y la igualdad de derechos. El Cotidiano, 202, 95-104.

Saucedo, B. (2012). Matrimonio y adopción por parejas del mismo sexo. El caso del D.F., México. [Tesis Doctoral]. Universidad de Barcelona.

Suárez, A. (2017). Usos e interpretaciones de la facultad de atracción en el juicio de amparo por la SCJN. En E. Ferrer Mac-Gregor y A. Herrera (Eds.), El juicio de amparo en el centenario de la Constitución mexicana de 1917 (pp. 47-64). Ciudad de México, México: UNAM. https://doi. org/10.22201/fder.24488933e.2014.262.60375 